\title{
estudes semiótices
}

\section{Leituras e escrituras em tempos de pandemia. Quarentenas, Quarenteninhas e Quaquarentenas, de Torero e Minkovicius*}

\author{
Luiza Helena Oliveira Silva*
}

\begin{abstract}
Resumo: Este trabalho analisa produções de três séries de pequenas crônicas escritas por José Roberto Torero Fernandes Junior e ilustradas por Ivo Minkovicius, publicadas diariamente no Facebook, ao longo de 2020, cobrindo o que pode ser compreendido como três momentos de percepção da pandemia provocada pelo Covid-19 no Brasil, ao menos no que diz respeito à sua experiência nas metrópoles. Intitulam-se respectivamente como Quarentenas, Quarenteninhas e Quaquarentenas. Mobilizando reflexões produzidas pelos estudos da literatura de testemunho e da semiótica, são analisadas, a partir da leitura de uma literatura vinculada ao cotidiano, as "traduções" da experiência de viver e sentir o acontecimento. À medida que se vivencia a duração da pandemia, muito além das previsões mais pessimistas, observa-se a atenuação do sentir o efeito inicialmente impactante de sua aparição, caminhando para uma anestesia que concorre para a indiferença quanto aos seus efeitos. Escrever, contudo, é ainda insistir no sentido sentido.
\end{abstract}

Palavras-Chave: literatura de testemunho; acontecimento; semiótica discursiva; pandemia; Torero.

* DOI: https://doi.org/10.11606/issn.1980-4016.esse.2021.181100 .

** Docente do Curso de Letras, do Programa de Pós-graduação em Letras e do ProfLetras, na Universidade Federal do Tocantins (UFT), campus de Araguaína, TO, Brasil. E-mail: luiza.to@uft.edu.br . ORCID: https://orcid.org/0000-0001-5886-6809 . 


\section{Introdução}

Não faça versos sobre acontecimentos.

Não há criação nem morte perante a poesia.

Diante dela, a vida é um sol estático,

não aquece nem ilumina.

[...]

O canto não é natureza

Nem os homens em sociedade.

Para ele, chuva e noite, fadiga e esperança nada significam.

A poesia (não tires poesia das coisas)

elide sujeito e objeto.

Carlos Drummond de Andrade, Procura da poesia

E m Procura da poesia, Carlos Drummond de Andrade (1985, p. 111-112) apresenta elementos de sua poética. Principiando com verbo do imperativo negativo, sintetiza já no primeiro verso a sua tese: a poesia não nasce de uma experiência imediata com os acontecimentos, não brota da relação sensível com objetos, o mundo natural, os sujeitos, mas do trabalho posterior, com a palavra mesma, com o que se situa no âmbito da linguagem. Diante disso, não se deve, pois, aquele que quer empreender a tarefa da escritura, seguir esse rumo infrutífero. Há que se voltar para uma outra esfera nomeada por ele como "reino das palavras", a ser penetrado com o devido respeito e cuidado, mediante os quais se podem finalmente encontrar os "poemas que esperam ser escritos". O acontecimento não seria, portanto, bom amigo da poesia e, por extensão, da literatura.

Principiamos por esses versos de Drummond porque nossas pesquisas vêm perseguindo justamente as produções que vão na direção contrária àquela indicada pelo mestre. Seriam as que podem ser compreendidas como "literatura de testemunho": textos que emergem como traduções da experiência do acontecimento ou, ao menos, de sua memória. Seria essa produção lida pelos teóricos como uma "boa literatura"? Essa questão particularmente não nos interessa responder, tanto pela complexidade e implicações que envolve, quanto pela direção que nos move como pesquisadora neste momento. Como alerta Coquio (2003, p. 343) ${ }^{1}$, parte do que se compreende como literatura de testemunho foi produzida por sujeitos que não eram inicialmente escritores, mas que tomaram para si a urgência de escrever:

${ }^{1}$ Trad. livre de: "La radicalité génocidaire et sa visée raciale, en particulier, placent les témoins dans une situation singulière : les membres de la collectivité visée ont la certitude d'être tous destinés à mourir ou de survivre par miracle - et de mourir pour rien. S'ils survivent, c'est alors pour écrire". 
A radicalidade genocida e sua perspectiva racial, em particular, colocam as testemunhas em uma situação singular: os membros da coletividade visada têm a certeza de serem todos destinados a morrer - ou de sobreviver por milagre - e de morrer por nada. Se sobrevivem, é então para escrever.

Para Klüger (2005), os versos infantis e de lírica rebuscada que produz nos campos atendem à necessidade de sobreviver ao efeito devastador da morte iminente, à loucura e ao desespero: "Quem só tem vivências, sem se preocupar com rimas ou pensamentos, corre o risco de perder a razão, como a velha sentada no colo de minha mãe. Nunca perdi a razão, compus rimas" (Klüger, 2005, p. 116). Contrapondo-se a Adorno, que diria que não se deveria escrever poema algum sobre Auschwitz, Klüger argumenta que "Essa exigência deve vir daqueles que podem prescindir da linguagem em versos, pois nunca a utilizaram ou dela necessitaram para manter-se psicologicamente com a cabeça fora d'água, sem afogar" (Klüger, 2005, p. 115). Escrevem, ainda, como Primo Levi (1988), em honra aos mortos, porque estes já não podem falar, ou, como argumenta Cru (1929), para desfazer as anedotas contadas sobre as guerras de todos os tempos, o tom épico que Ihes conferia até então a literatura, para denunciar falsificações da história ou ilusões da arte, "para revelar que a guerra é 'feia, suja e perversa', que nela se vive com medo e nela se morre mediocremente" (Cru, 1929, p. 226 apud Lacoste, 2007, p. 3)².

De nossa parte, o que perseguimos é a compreensão do que se diz no instante da vivência do acontecimento ou, passado o efeito impactante de sua aparição, que se produz enquanto perduram seus efeitos sobre aquele que escreve. Que legibilidade, afinal, se produz no/para o acontecimento?

No contexto europeu, a escritura do testemunho compreende as produções relacionadas a grandes catástrofes e genocídios, como os que se sucederam no contexto das duas grandes guerras. Em um curso oferecido entre 2013 e 2014, no Collège de France, Compagnon aborda diferentes perspectivas para pensar a relação da literatura com a guerra: luta com as palavras, com a tradição, entre modelos e correntes, mas também a que de certo modo traduz sua vivência na guerra mesma, aquela mais real e menos metafórica. Neste último caso, analisa a ocorrência de produções de natureza fantástica escritas por sujeitos - muitos deles não tendo antes a experiência de escritores, como discutem Coquio (2003) e Compagnon (2014) - na "tradução" do vivido, "caracterizada tanto pela incompreensão e confusão no campo de batalha quanto pelo sentimento paradoxal de férias, de festa, de carnaval experimentado pelo combatente" (Compagnon, 2014, p. 668)³. É o combatente, sob o fogo do

2 Trad. livre de: "révéler que la guerre est « laide, sale et méchante » (1929: 226), que l'on y vit dans la peur, et que l'on y meurt mediocremente".

${ }^{3}$ Trad. livre de: "caractérisé tant par l'incompréhension et la confusion sur le champ de bataille que par le sentiment paradoxal de vacances, de foire, de carnaval éprouvé par le combattant". 
inimigo, que escreve, na vivência do sem-sentido do acontecimento. E escreve, sobretudo, cartas, o que leva a considerar como um "butim de guerra" as cartas dos inimigos mortos (Compagnon, 2014, p. 666).

Considerando o contexto brasileiro contemporâneo, perguntamo-nos se é possível ultrapassar os efeitos de devastação do real sobre nós e produzir literatura, num momento em que, como brasileiros, estamos sob o impacto de dois acontecimentos que se superpõem: o da crise institucional que fragiliza a democracia, num processo que se inicia com o golpe - travestido de impeachment - contra Dilma Rousseff (2015-2016) e se intensifica com a posse de Bolsonaro (2019); o da pandemia provocada pelo Covid-19 (2020) e as medidas que dizem respeito ao seu (não) enfrentamento por parte do governo federal, contando para isso com o apoio dos segmentos da sociedade que se alinham ao projeto neoliberal e autoritário em curso.

Como um acontecimento dentro de outro acontecimento, a pandemia sofre com os reveses da política de negação da gravidade do que nos ameaça. No primeiro momento, deu-se a percepção tônica do acontecimento sentido como tal, com súbitas mudanças no cotidiano que implicaram o enclausuramento de parte da população, medidas drásticas de prevenção como fechamento de escolas, comércio, igrejas, academias, lockdown etc. Inserida no âmbito da duração, a experiência segue o processo de atonização que produz como efeitos a indiferença quanto ao quantitativo de mortos e a redução drástica com os cuidados. É como se, seguindo uma lógica de orientação mágica e operando sob o modo da negação, ela pudesse ser ignorada na sua gravidade e, assim, deixasse de ser sentida, não mais existindo como ameaça: "o que os olhos não veem o coração não sente".

A noção de acontecimento necessariamente implica a dimensão do sensível, quando um sujeito se ressente de uma dada configuração da ordem das coisas que vai desordenar o já sabido e o já experienciado. A novidade intensamente sentida, inclusive por seu caráter inesperado, aturde o sujeito, subitamente incapaz de poder responder, porque, para isso, estaria implicado algum afastamento que tornasse possível a mobilização da linguagem e da razão. Passado o instante de torpor, ainda que intensamente afetado, o que se pode dizer?

Para a semiótica tensiva, o sujeito que se inscreve no acontecimento é destituído momentaneamente de seu status como tal, passando à condição de não-sujeito, aquele que se pode apenas sentir, levado pelo turbilhão do fluxo das coisas. Narrar, então, será possível apenas num momento posterior, quando o vivido já se faz memória e a tonicidade da experiência se desfaz pela introdução da duração, expandindo-se como extensidade (Zilberberg, 2011; Silva, 2016). 
Como testemunhas, deveríamos narrar nosso tempo, respondendo à convocação da memória e da urgência de produção de sentidos. Quem ousa enunciar a resistência, organizar o verbo, pôr em marcha as sílabas em boa métrica e ritmo, instaurar-se como sujeito capaz de enunciar mais do que o espanto, mesmo embrenhado no absurdo, sob os efeitos do caos do acontecimento? Buscamos aqui tratar mais especificamente da resistência na literatura, que se insurge como meio de dizer esse tempo, na busca do enfrentamento do aqui-agora do vivido e no qual se deve enunciar. Os textos que iremos analisar parecem situar-se entre dois pólos que implicariam a impossibilidade de dar sentido em função da "marginalidade do sujeito", o da "dor" e o do "enfado" 4 . Nesse caso, a dor remete ao acidente/acontecimento e sua tonicidade excessiva, enquanto o enfado corresponde ao estado do sujeito inscrito na regularidade e previsibilidade da extensidade e sua consequente atonia.

\section{Diários do tempo da quarentena}

Para tratar dessa escritura do acontecimento, selecionamos textos que compõem parte do acervo de leituras a que nos dedicamos nesses tristes meses de 2020: sequências de crônicas breves produzidas por José Roberto Torero Fernandes Junior, mais conhecido como Torero, agrupadas sob os títulos Quarentenas, Quarenteninhas e Quaquarentenas e ilustradas por Ivo Minkovicius. No momento em que escrevemos, Torero dedica-se à terceira série. Esses textos encontram-se disponíveis na página do autor no Facebook (Cf. https://www.facebook.com/joserobertotorero), tendo sido compartilhados como registros diários da vida na pandemia, sob diferentes perspectivas. Não nos lembramos de como se deu nosso encontro com as séries, mas, desde a primeira vista, firmamos o propósito de acompanhar suas produções. Como procuramos mostrar, esses relatos que tomam o cotidiano como tema vão narrando a experiência brasileira com a pandemia provocada pelo Covid-19, traduzindo da percepção maior da doença como acontecimento - nas duas primeiras séries a sua neutralização e apatia - na última.

O dicionário online Dicio apresenta seis acepções para o verbete quarentena, que teria como sinônimo o vocábulo "isolamento". A primeira acepção fornecida pelo dicionário é a de que corresponde ao número exato ou aproximado de quarenta dias. Para a Medicina, o período compreendido por essa denominação seria relativo, a depender do tempo necessário para combate à propagação de uma dada doença. Por extensão, estaria relacionado ao tempo de isolamento a ser imposto a pessoas e mercadorias oriundos de países que sofrem com doenças contagiosas. Nessa mesma perspectiva, no âmbito da Marinha,

\footnotetext{
${ }^{4}$ Os termos em destaque são subtraídos de Interações arriscadas (Landowski, 2014).
} 
trata-se do isolamento de um navio proveniente dessas localidades. Na esfera popular, pode referir-se ao período de privação sexual. Para a religião, encontra correspondência com o termo quaresma (Cf. https://www.dicio.com.br/quarentena/ Acesso em: 14 set. 2020).

Como evidencia o Aurélio, não há tanta precisão com relação ao quantitativo de dias compreendidos pela denominação quanto se poderia inicialmente prever pelo radical da palavra. Iludidos pela dimensão numérica, poderíamos acreditar que, esgotados os 40 dias iniciais de isolamento imposto com certo rigor no início da pandemia de Covid-19, os riscos de contágio e morte teriam sido eliminados, o acontecimento estaria encerrado e a vida ressurgiria, ainda que sob um "novo normal". Na sequência dos meses, porém, a pandemia agravou-se, sem sinais de superação. Do sentimento de torpor e espanto que acometia a uma maioria e que fazia com que se observasse rigor no enclausuramento (ao menos para aqueles que podiam gozar desse benefício sem a obrigatoriedade do trabalho presencial), passamos para o da dessensibilização e apatia, que faz ignorar os números crescentes dos mortos e a fragilidade do atendimento médico aos doentes. Do medo e compaixão parecemos ter alcançado a sublime indiferença e, assim, concluímos que, se dizer o acontecimento é da natureza do impossível (dor), dizer a rotina parece apontar para uma prática inútil (enfado).

Fiel ao senso numérico, o primeiro projeto de Torero, Quarentenas, seguiu a perspectiva da produção de quarenta crônicas devidamente enumeradas, compartilhadas na rede social ao longo de quarenta dias, nos meses de abril e maio de 2020. Principiamos por descrever e relacionar o que se mostra inserido no eixo da regularidade.

Os textos curtos, como crônicas breves, obedecem a uma espécie de moldura, apontando para a repetibilidade de uma fórmula, sua estabilização do ponto de vista do plano da expressão. A concisão atende à lógica de consumo de textos na Web, disputada a atenção do internauta com um turbilhão de outros à disposição. Particularmente no Facebook, os grandes textos são pouco lidos, mesmo quando muito comentados, o que se faz a partir do título, das imagens, da temática, muitas vezes resultando em equívocos que evidenciam a displicência quanto à leitura ou, mesmo, a má fé, no desrespeito a uma "ética da leitura", quando o leitor se porta como "um pequeno soberano" em sua "deriva interpretativa" (Landowski, 2004, p. 23). O suporte, portanto, constrange a escrita, pressupondo um leitor acelerado e, por isso mesmo, desatento. Para evidenciar essa permanência que caracteriza e particulariza cada série, trazemos inicialmente as Figuras 1 e 2 (Cf. abaixo).

Os textos têm como cenário a metrópole e o narrador se apresenta como um sujeito que, dotado de um telescópio, pudesse espiar por dentro dos prédios 
o que acontece com outros, subitamente subtraídos de seu anonimato de elemento indistinto na multidão, toda ela trancafiada pela imposição do confinamento, correspondendo à primeira fase da percepção da pandemia. Em Quarentenas-40, a última da primeira série, Torero figurativiza esse narrador que encerraria naquele momento o projeto, cumprida a missão a que fielmente se dedicara:

Há quarenta dias ele está ali, atrás das cortinas, usando um telescópio possante para bisbilhotar a vida dos outros. E a cada dia descobre, ou inventa, uma história para cada uma daquelas janelas.

Hoje finalmente ele vai parar. Completa quarenta histórias e fazer mais de quarenta numa quarentena não parece certo. Há que se respeitar o nome das coisas.

Ele desmonta o telescópio lentamente, guarda-o com cuidado na caixa e diz para si mesmo que por um bom tempo não quer saber mais dessa tal de covid-19.

Mas aí tosse. (Fernandes Junior, 2020, s/p)

Figura 1: Print de Quarentenas - 34

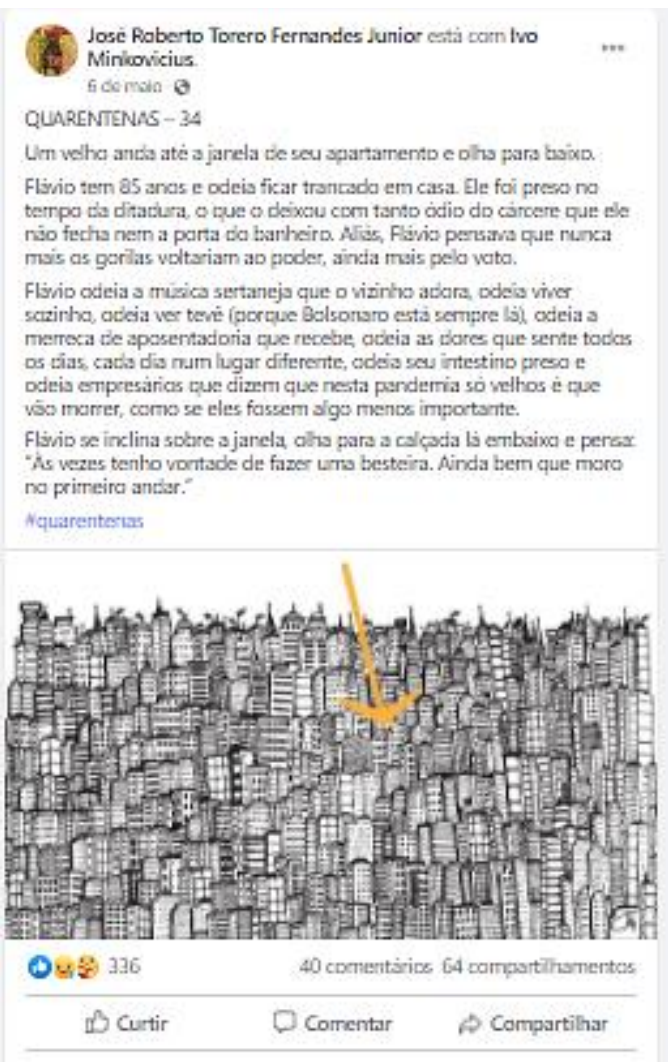

Figura 2: Print de Quarentenas - 39

José Raberto Torero Fernandes Junior eți carn lvo Minlorvicius. QUARENTENAS - 39

Andrè da Silva, vulgo "Dedé Chinguilingui", importadoc, 30 anco,

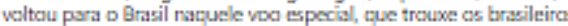
que estavarn em Wukan, ra Ching

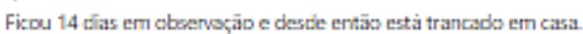
Chinguilingui sertia alivio por escapor to epiderria cue se alstrarat Sertid cue tirha driblado a marte cotse

Porèm, agara ele está com medo. O Brasil já tem quase trés vezes o mulrero de mortas da China e a caisa nso para de crexcr. Chinguilingui vé o peesidente liberando os salóes de belezs, as acadernias de ginistica e as barbeires, e peres que nio sdisnta nads morrer de unhas feitar com abobarnen defiritlo e barba bem aparads Eke vé churrascos sendo marcation, pesscoss sem mascaras pelas ruas e ónibus lotadas.

Chiguilingui estas tentando cocrorar uma passagem para a China Max está difici. Se nũo corereguir, vai para a It ília mesmo. *iquarentersa

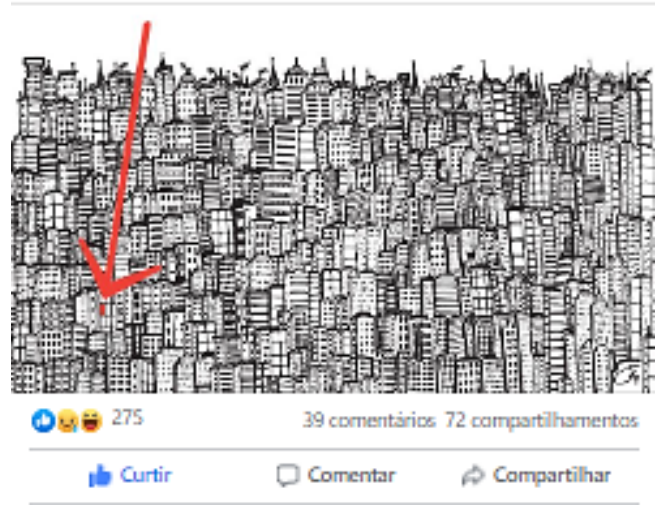

Fonte: Ambas disponíveis em https://www.facebook.com/joserobertotorero. Acesso em 14 set. 2020. 
As narrativas nasceriam, portanto, daquilo que esse voyeur fosse capaz de apreender pela percepção - "descobre" - ou produzir pela imaginação "inventa". Finalizado o projeto, o narrador que fala do narrador como um outro (pela debreagem actancial enunciva) insinua a possibilidade mesma de sua morte: "Mas aí tosse".

\subsection{Da paisagem}

A paisagem é sempre a mesma, dada pela reiteração da imagem em preto e branco, tendo como variável no recorte apenas uma seta colorida que vai mudando de posição, como que servindo para ancorar o lugar, o aqui/lá onde se situam os personagens (Figuras 1 e 2 ).

A verticalidade das edificações na cidade ali se registra, mal definindo os limites de cada prédio, confirmando a cidade como um contínuo, uma regularidade arquitetônica que se expande horizontalmente até as margens laterais do desenho para sinalizar, pelo inacabamento, que segue além.

Confirma-se na imagem de cidade a contiguidade que leva Landowski, em seu texto sobre os regimes de espaço, a mobilizar a metáfora do "tecido" para tratar da espacialidade operada pelo regime da "programação": "É o mundo fechado, saturado e reconfortante, da contiguidade das coisas entre si" quando, conforme explica o semioticista, tudo se sustenta "organicamente ou mecanicamente como em um relógio” (Landowski, 2015, p. 11).

Nessa espacialidade situada sob a lógica da continuidade e contiguidade, instaura-se a máxima previsibilidade, tendo como resultantes 'mecanismos' que regulam rigorosamente - que 'programam' - as interações entre os elementos com os quais os homens fabricam seu ambiente" (Landowski, 2015, p. 18). Assim, a cidade figurativizada na ilustração dos contos confirma a metáfora do tecido, aquele que determina modos de ser e estar no (sem) sentido, porque tudo se faz sob o comando da programação, reduzindo os sujeitos a meros "operadores" (Landowski, 2014; Greimas; Courtés, 2008).

Na margem superior, quando se anuncia o espaço em branco, desenhase no alto dos prédios as antenas, essas que tornam possível a comunicação incessante, o burburinho de vozes, o cruzamento de textos, o excesso que parece impedir a emergência de qualquer singularidade, impossibilitando toda escuta e efetivo diálogo. A seta que se sobrepõe como uma espécie de rasura é o que quebra a monotonia das formas e cores, servindo para situar o leitor no espaço mais circunscrito onde se desenrolam os acontecimentos trazidos pela narrativa breve. É a seta que recorta o espaço indiferenciado, reclama a existência do sujeito enunciador, esse de que trata a prosa sob a numeração do dia, projetando no enunciado o gesto do sujeito da enunciação. A cada publicação, altera-se apenas sua posição e cor, que vale para instaurar, no espaço figurativizado do 
enunciado visual, o gesto que acena para a existência de um ele, de quem se fala, num dado lá, num tempo de então. O acontecimento é então registrado como um olhar para fora, em busca da percepção do que o outro sente e sofre.

Na Figura 1, a cor é laranja, em inclinação que a distingue da predominância dos sentidos impostos pela reiteração conferida pelo alinhamento dos prédios verticais. Sinaliza ainda em registro quase imperceptível um ponto no espaço, aquele para o qual se deve olhar para compreender onde se encontra aquele de que se fala, no caso em questão, o Flávio.

Na Figura 2, a transformação, que confirma a narrativa se desenvolvendo também na sequência de imagens, se dá pela mudança de cor e posição da seta, como uma enunciação enunciada. Esta agora é maior e na cor vermelha, apontando no enunciado visual para o lugar que ocuparia no espaço aquele sobre o qual se fala, André da Silva, vulgo Dedé Chinguilingui, empresário da área da exportação que quer retornar para a China, de onde partira no início da pandemia. Selecionamos para análise o texto de Quarentenas-34, que traz a história de Flávio.

\subsection{Do sofrer}

No texto composto por três breves parágrafos, encontramos o único personagem, Flávio, sem sobrenome, com 85 anos, indignado com o cerceamento imposto pela quarentena. Seu desejo de liberdade o leva a negar-se a fechar até mesmo a porta do banheiro, como gesto de quem rejeita todo tipo de cárcere. Tem a memória da prisão durante a ditadura, o que indica sua vertente ideológica confirmada ainda na juventude, como também a continuidade de seu inconformismo, a vontade de resistir que perdura na velhice. Indignado, recusa a compreender como os militares ("gorilas") puderam retomar o poder pelo voto, numa opção que trai o passado próximo, quando o governo militar se instalou por um golpe de Estado.

É explícita a razão de seu desconsolo: o descaso quanto à ausência de políticas de combate à pandemia, que ceifaria, sobretudo, os mais velhos. Ecoa ali a opção enunciada pelo então ministro da Saúde ${ }^{5}$, que, sob a lógica da mesma triagem dos campos de concentração nazista, condena de antemão à morte os idosos, porque já viveram o suficiente, para salvaguardar os jovens, força de trabalho. Flávio é sujeito passional, tomado pela paixão do ódio, que se confirma na reiteração de malquerença quanto à música sertaneja compartilhada pelo vizinho, à solidão, à televisão que atualiza a figura do presidente, ao salário de aposentado, às dores do corpo e seu mal funcionamento, aos empresários que

${ }^{5}$ Cf. Valente, 2020. 
evocam as preocupações de natureza econômica antes da atenção com a preservação da vida.

A velhice é ali figurativizada, a partir dos estados de alma do sujeito, como ruína, como momento de decadência física e fragilidade, mas principalmente por uma não conformidade quanto às escolhas das gerações mais novas: o gosto musical, a opção política, o discurso hegemônico, a traição da história recente. Pensa então num último gesto, caracterizando a resistência à condenação anunciada, dando cabo da existência pelo suicídio. Pular do primeiro andar, contudo, não garantiria o sucesso pretendido, o que aponta para a negação da ruptura pretendida e, portanto, para o estado inalterado do estado de alma do sujeito.

Fica explícita a referência ao ator Flávio Migliaccio, com a mesma idade do nosso personagem, que se suicidara dois dias antes, conforme noticiado amplamente pela mídia. Cruzam-se aqui as histórias, a real e a ficcional. $\mathrm{Na}$ história do Flávio ficcional, é possível escutar a narrativa do ator, o Flávio ator do mundo natural, que registra em carta seu desconsolo, a opção por partir, como atesta trecho citado em site da Revista Isto É ao noticiar sua morte: "Me desculpem, mas não deu mais. A velhice neste país é [...] como tudo aqui. A humanidade não deu certo. $A$ impressão que foram 85 anos jogados fora num país como este e com esse tipo de gente que acabei encontrando. Cuidem das crianças de hoje" (ATOR, 2020).

O Flávio real encontra o caminho da ruptura, fugindo à condenação da programação da metrópole sob os efeitos da ditadura eleita como solução para o país. No balanço do que viveu, conclui que foi um grande tempo "jogado fora", o que o faz decidir por abreviar a duração. O Flávio ficcional não encontra saída, nem tem esperança, ainda que em pequenos gestos registre a não-conformidade.

\subsection{Mesmo cenário, outros personagens}

Inicialmente órfãos pela finalização da primeira série, os leitores reencontram em junho de 2020, no Facebook, uma nova proposta de Torero e Ivo Minkovicius com Quarenteninhas. Do ponto de vista do gênero e seu formato, a fórmula se mantém, mas o título com o emprego do diminutivo cria um neologismo que vai denunciar a instauração de personagens crianças, quase sempre em diálogo com os pais e situados numa cena doméstica. Trata-se de uma proposta mais delicada de abordagem de temas complexos, tendo em vista a possível inclusão de um universo de novos leitores: o público infantil (Cf. Figura 3 e Figura 4, abaixo).

Para a ilustração, o gesto é capaz de criar uma nova percepção para a retomada da mesma cidade da série anterior. O fundo branco ganha cores fortes, que se modificam a cada dia, o que contribuiu para traduzir as transformações 
da narrativa pela expressão visual. Do mesmo modo, multiplicam-se as cores nas janelas dos prédios, fazendo com que se veja uma cidade mais iluminada e, portanto, mais eufórica como representação. A seta então se faz um braço alongado com um dedo indicador apontando para precisar na imagem o espaço ocupado pelo personagem da narrativa. Como enunciação enunciada, os traços dessa mão, que se introduz no desenho da metrópole, lembram o gesto comum de crianças de apontar o dedo para precisar aquilo de que se fala. Desse modo, a seta mais impessoal da série Quarentenas agora ganha a presença metonímica de um corpo em Quarenteninhas.

Figura 3: Print de Quarenteninhas - 30

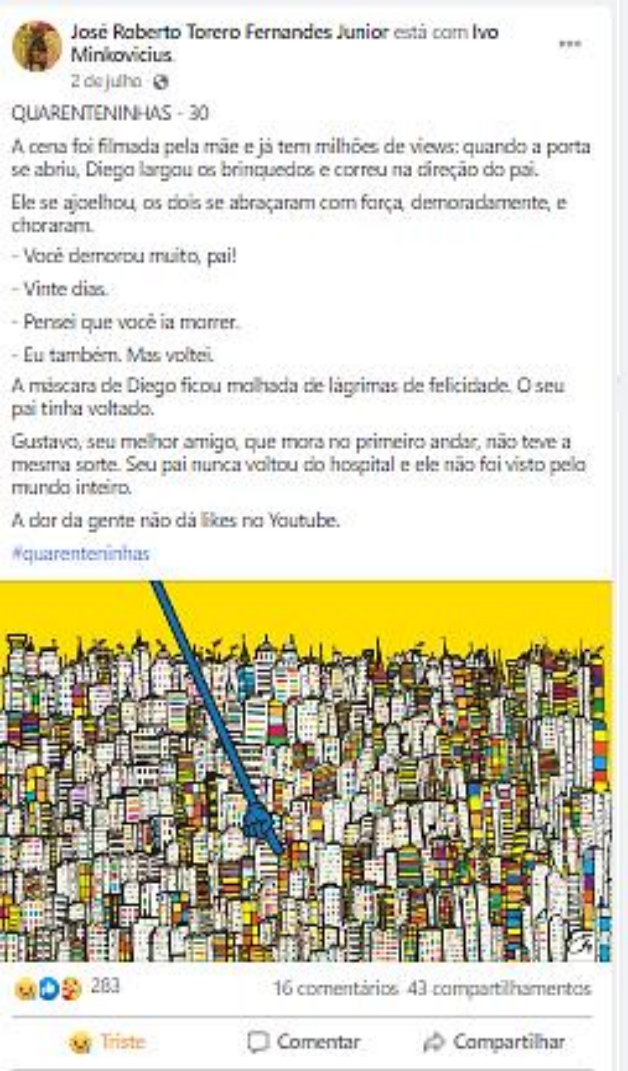

Figura 4: Print de Quarenteninhas - 36
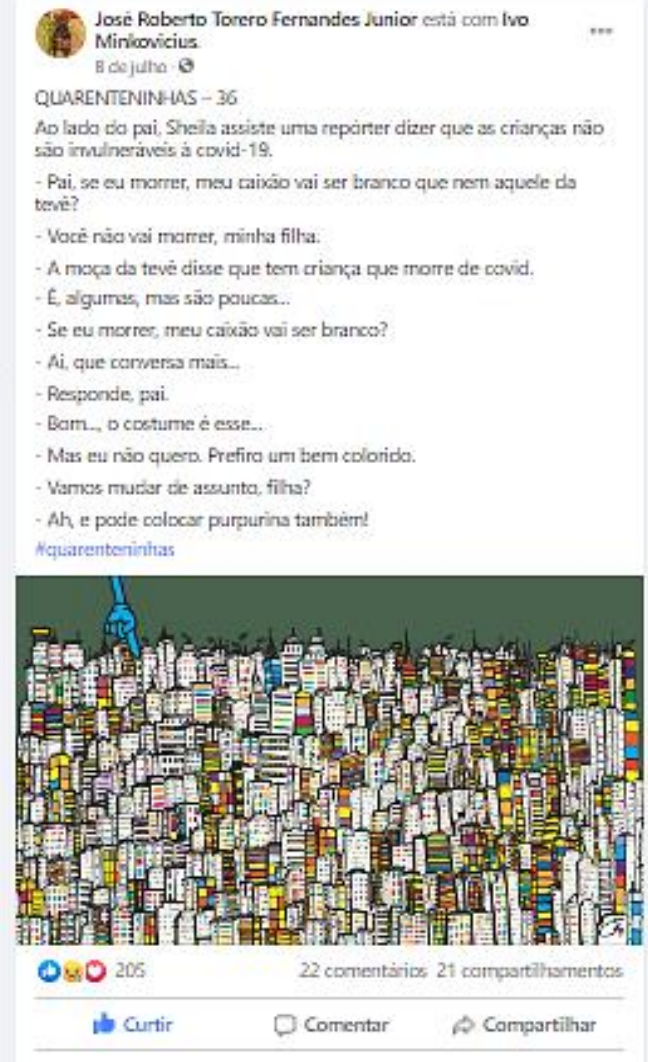

Fonte: Ambas disponíveis em https://www.facebook.com/joserobertotorero Acesso em 14 set. 2020.

Nos dois textos de Quarenteninhas (30 e 36), encontramos o tema da morte. No primeiro, o menino Diego corre para os braços do pai, que regressa do hospital depois de uma internação que durara vinte dias. A falta é sentida pelo menino como longa demora, intensificada pelo medo de que o pai pudesse não 
se recuperar: "Pensei que você ia morrer". A cena feliz do reencontro e seu diálogo é registrada pela mãe em vídeo a ser compartilhado na Internet, tendo sucesso explicitado pelos milhões de visualizações. A imagem feliz, no entanto, é interrompida pelo narrador, ao trazer a nova informação: o pai de Gustavo, amigo de Diego e residente no mesmo prédio, falecera. O falecimento é então a ausência de imagens - "nunca mais foi visto pelo mundo inteiro" -, uma desaparição súbita, que não pode ser registrada: "A dor da gente não dá likes no Youtube". Se a alegria pode ser efusivamente compartilhada, o luto é solitariamente sentido. Pela gravidade dos riscos implicados pela contaminação, não há corpo a velar, não há rituais de sepultamento, só a lacuna da partida repentina. Nessa frase final da narrativa, ecoa o verso de uma composição de Luís Reis e Haroldo Barbosa - "A dor da gente não sai no jornal" - agora atualizada com as novas práticas de produção e consumo de notícias. Décadas após de escritos os versos de Joana (1961), o sofrer ainda não encontra bom eco na mídia.

Em Quarenteninhas 36, a mídia está também presente na cena familiar. Sheila vê pelo noticiário que as crianças também podem morrer por Covid-19. O pai tenta fugir ao diálogo difícil com sua filha, que insiste em perguntar sobre o que aconteceria caso morresse como se sucedeu com a criança de que fala a TV. Indiferente à compreensão da morte, Sheila quer detalhes sobre como seria seu caixão, se seria também ele da cor branca e se poderia ter ainda purpurina. Nessa crônica, o olhar infantil dribla a percepção do sofrimento, quando a morte the parece quase uma festa.

Pelos recursos da cor, da nomeação dos atores e emprego do diminutivo, os textos quebram a regularidade da cidade/tecido, como registro de uma escuta mais amorosa. Novamente, o narrador do acontecimento busca a percepção do outro, sem falar de si mesmo, numa tensão entre escolhas que contribuem para efeitos de aproximação e afastamento.

\subsection{De volta às ruas}

A terceira série, Quaquarentenas, é produzida por Torero a partir de setembro. Há novamente modificações na ilustração, apontando simultaneamente para a continuidade - que a faz sequência das anteriores - e para a transformação - que mostra a nova perspectiva assumida pela narrativa e pela figurativização da cidade.

É a mesma metrópole em preto e branco (Cf. Figura 5 e Figura 6, abaixo), mas o desenho de Minkovicius acrescenta nesse momento corpos humanos em primeiro plano, figurativizando a ruptura com o enclausuramento nesse momento da pandemia. As figuras humanas registradas na cor preta e chapada sobre o fundo branco distribuem-se horizontalmente ao longo da faixa inferior da imagem. Solitárias ou acompanhadas, estacionadas ou em movimento, 
perfazem a agitação da cidade, a multidirecionalidade e a dispersão no passeio. Lá estão crianças e adultos, homens e mulheres. Como sombras moventes frente à cidade estática e igual ao fundo, traduzem a vida pelo movimento, mas sob a tônica da mesma indistinção e anonimato. A seta que atravessa o desenho novamente quebra esse contínuo para precisar as figuras humanas destacadas do conjunto por receberem uma cor distinta como a sinalizar que a cena breve tem essas figuras como atores.

Figura 5: Print de III (série Quaquarentenas)

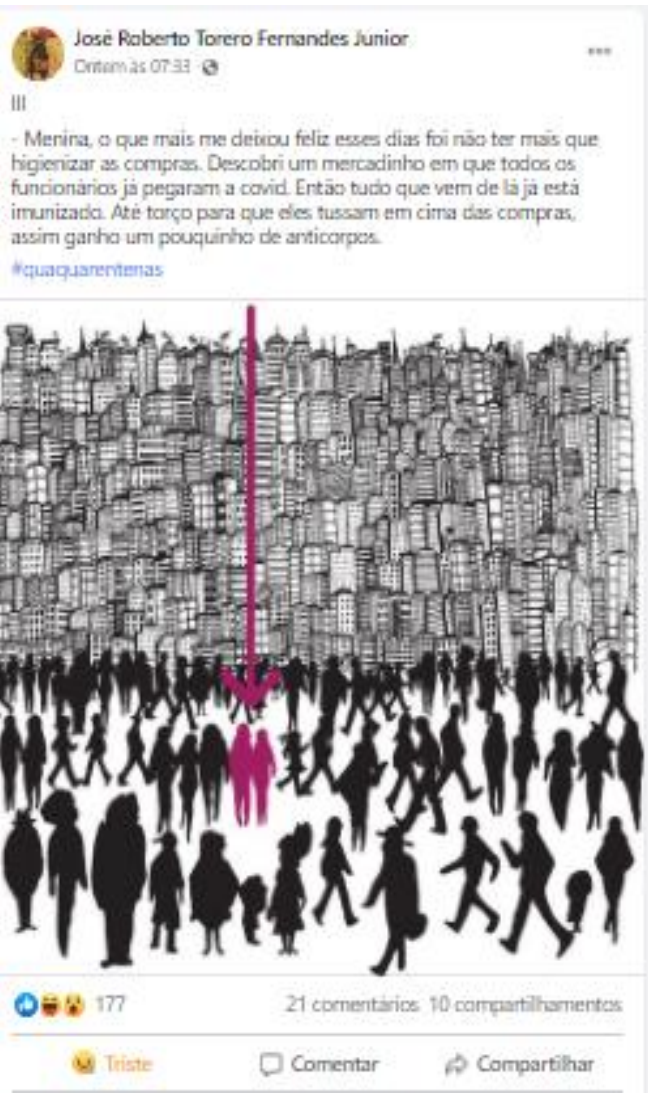

Figura 6: Print de IV(série Quaquarentenas)

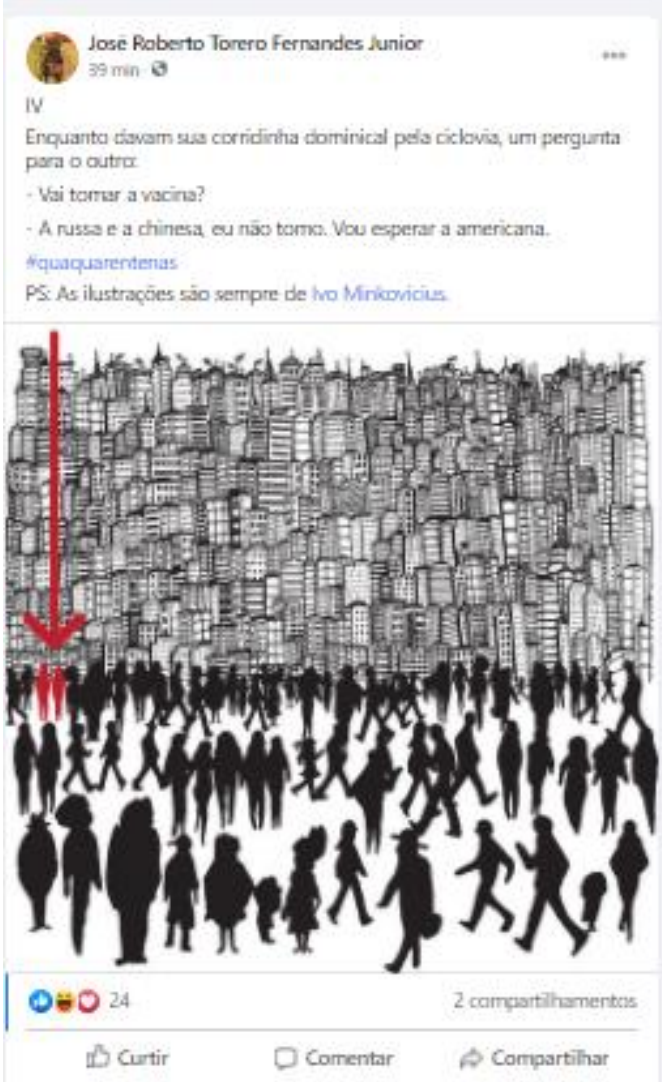

Fonte: Prints de seções da página de Torero. Ambas disponíveis em https://www.facebook.com/joserobertotorero Acesso em: 14 set. 2020.

Os textos trazem a numeração crescente, sem o título da série ao seu lado. A identidade da nova proposta aparece ao final, numa hashtag (\#quaquarentenas). Além desses elementos imediatamente visíveis, analisemos o que os singulariza, considerando suas regularidades. 
Enquanto em Quarentenas e Quarenteninhas tínhamos o diálogo entre sujeitos identificados por seus nomes, em Quaquarentenas a diferença dos interlocutores é marcada pelo travessão que indica a troca de turno. No texto III (Figura 5), apenas uma pessoa fala, reportando-se ao interlocutário como "menina"; no texto IV (Figura 6), o narrador os situa pelo emprego de pronomes indefinidos - "um" e "outro".

No texto III, o ator, não identificado sequer quanto ao gênero, comemora o fato de não precisar mais higienizar as compras por ter descoberto um mercadinho cujos funcionários já foram todos acometidos pelo Covid-19. Para esse ator, trata-se de uma boa vantagem: "Então tudo que vem de lá já está imunizado. Até torço para que eles tussam em cima das compras, assim ganho um pouquinho de anticorpos".

Nesse registro, há apenas essa voz, que ecoa, contudo, discursos dos que saúdam "a vida que segue", sem dar fé dos milhares de mortos, do sofrimento produzido pelas perdas, dos necrológios que se anunciam cotidianamente nas redes, do luto produzido pela partida de tantos, com histórias irremediavelmente interrompidas e perdidas. Registra-se a fala da sublime indiferença e, mesmo, o cinismo de quem não se compadece do fato de que, no caso específico em questão, trabalhadores tenham sido infectados. A pessoa comemora os benefícios pessoais, ainda imaginando lucrar com possíveis anticorpos. Se a fala é atribuída a um ator anônimo, a indistinção de quem o profere assinala que possa ser recuperada da fala de muitos, que vão construindo consensos de discursos e práticas.

No texto IV, os interlocutores discutem a opção pela vacina, até o momento não disponível. A pergunta do primeiro personagem considera algumas possibilidades, como a de que não houvesse interesse na imunização, tendo em vista o movimento crescente antivacina que, nas manifestações do Dia da Independência, levou alguns de seus partidários no Brasil para as ruas (Cf. Figura 7, abaixo). O segundo personagem responde: "A russa e a chinesa eu não tomo. Vou esperar a americana" (Torero, 2020, s/p).

Laboratórios de diferentes países se concentram na produção de uma vacina que seja capaz de frear a pandemia, mas a fala do personagem explicita uma oposição de outra natureza e que atravessa o momento atual, retomando os tempos da Guerra Fria e o intenso anticomunismo. Para estes, o mundo novamente se acha novamente dividido em dois pólos e a saúde é submetida ao viés ideológico. 
Figura 7: Imagem de manifestantes antivacinação (editada pelo autor para não identificar os sujeitos da foto).

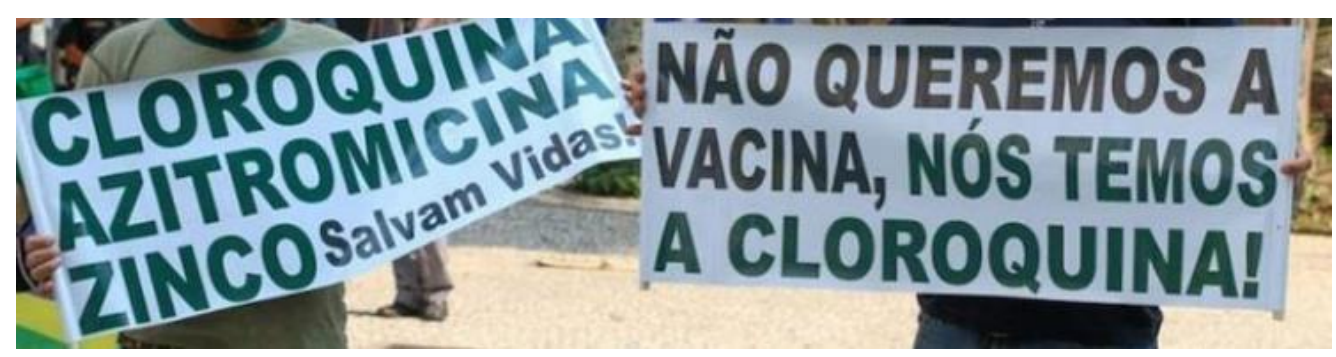

Fonte: http://www.semanaon.com.br/conteudo/16460/suspensao-em-oxford-e-bolsonaro-excitamconspiracionistas-antivacinacao Acesso em: 18 set. 2020.

Os diálogos trazidos por Torero não fazem necessariamente rir, como a onomatopeia incorporada pelo neologismo - quaquá - pode sugerir. A filiação ideológica dos atores é evidente. Quem diz uma fala pode dizer a seguinte, porque comungam da mesma perspectiva diante da pandemia, como também diante da política. São enunciados que emergem sem uma origem tão precisa mas que produzem consensos junto aos grupos mais à direita no atual contexto do país. Em alguns casos, presentificam discursos de ódio, racismo, niilismo, ainda mais explícitos no texto VII, publicado no dia 17 de setembro: "Cara, fui numa sorveteria e a menina do balcão não quis me atender porque eu estava com a máscara no pescoço. Xinguei a palhaça de tudo quanto é nome, quebrei coisa, ameacei, fiz um escarcéu. Pô, na lei não está escrito que ela tem que estar em cima da boca" (Torero, 2020, s/p). Associando aos estudos de Barros (2016) sobre os discursos intolerantes, temos a enunciação de paixões malevolentes, enquanto a filiação ideológica de posições conservadoras extremadas concorre para a confirmação da programação que torna previsível e pré-formado o dizer. Nesse sentido, há corpos, não necessariamente sujeitos, mas operadores.

A cidade antes iluminada de Quarenteninhas agora se apaga, retornando à sua condição de tecido. A recuperação do desenho de Quarentenas reitera a regularidade e a previsibilidade de uma cidade sempre a mesma. Ainda que a presença de sujeitos nas ilustrações traga mais elementos para pensar a dimensão do corpo sensível na metrópole, seu apagamento pela cor concorre para reiteração da indiferença projetada nos diálogos. Uma linha vertical separa os espaços da cidade e dos atores, acentuando uma quase disjunção. A cidade/tecido permanece assim como impenetrável, impondo um dever ser, um estilo de vida, uma programação que predefine modos de ser e estar. Em Quaquarentenas, materializa-se a conformação à distopia. 


\section{Considerações finais}

Nosso texto discorre sobre a produção de duas séries de Torero e Minkovicius, então finalizadas, e outra que, no momento em que o produzíamos, ainda se encontrava em processo de escritura. Ambas trazem em comum o tema da quarentena, mediante a vivência de uma pandemia que se prolonga no Brasil por quase um ano. Na sucessão dos textos, vemos, mediante as falas dos atores nas cenas descritas, as transformações da percepção do país diante do que se compreende como acontecimento. Ficção e realidade aí se imbricam, num projeto que explicita um engajamento crítico e político, atravessado pelo humor, pela ironia, mas também pela dor de viver e dizer esse instante que passa.

Como registros diários postados nas páginas do Facebook, cumprem o esforço da crônica, narrando o presente enquanto este acontece, compreendendo o presente como "coincidência do acontecimento descrito com a instância do discurso que a descreve" (Benveniste, 2006, p. 289). À medida que o tempo avança, as percepções se deslocam, indo do espanto inicial e sofrimento pelas mortes ao extremo da anestesia, que se traduz nos comportamentos de recusa, indiferença, descaso.

A cidade das imagens de Minkovicius se ilumina pelas cores quando os atores são crianças, mas se apaga novamente pela oposição em preto e branco que figurativiza a cidade como tecido, organização espacial para o qual não se pode dar sentido. $O$ gesto breve de descontinuidade pela seta e pela cor diferente sobre uns e outros não é capaz de abalar a regularidade, a previsibilidade, a indistinção. Tudo funciona, como diria Landowski (2015), como um relógio, e, como peças de uma engrenagem, não cabe bem o muito sentir.

A programação está na fórmula dada pelo gênero, pela repetição devidamente numerada, pela imagem sempre a mesma. Se há salvação contra essa condenação ao sem-sentido, esta se faz pela enunciação: é ainda necessário dizer, ainda que poucos ainda ouçam ou sejam capazes de lamentar.

Escrever é insistir na razão, como declaram os relatos de Klüger (2005), mesmo quando tudo parece apenas paráfrase, repetição do consenso de sujeitos em conformidade com a sua condenação. Se possível, façamos versos sobre acontecimentos, ainda que maus, porque se trata mais do que nunca de uma estratégia necessária na luta pelo sentido. 


\section{Referências}

ANDRADE, Carlos Drummond de. Nova reunião. 19 livros de poesia 1. 2. ed. Rio de Janeiro: José Olympio, 1985.

ATOR Flavio Migliaccio comete suicídio e deixa carta. IstoÉ Gente, 04 mai. 2020. Disponível em: https://istoe.com.br/ator-flavio-migliaccio-deixa-carta-apos-suicidio/. Acesso em 07 mai. 2020.

BARROS, Diana Luz Pessoa de. Estudos discursivos da intolerância: o ator da enunciação excessivo. Cadernos de Estudos Linguísticos, v. 58. n. 1. 2016. p. 7-24.

BENVENISTE, Émile. Problemas de linguística geral II. 2. ed. Campinas: Pontes, 2006.

COMPAGNON, Antoine. Cours: la guerre littéraire. 2014. Disponível em: https://www.collegede-france.fr/media/antoinecompagnon/UPL1605695926122941233_0661_0682_Compagnon.pdf. Acesso em 29 out. 2020.

COQUIO, Catherine. L'emergence de une "littérature" de non écrivains: les témoignages de catastrophes historiques. Revue d'Histoire Littéraire de la France. n. 2. v. 103. 2003. p. 343362.

$\mathrm{CRU}$, Jean Norton. Témoins. Essai d'analyse et de critique des souvenirs de combattants édités en français de 1915 à 1928. Paris: Les Etincelles, 1929. [Réed. Presses Universitaires de Nancy, 1993.]

FERNANDES JUNIOR, José Roberto Torero. Quarentenas - 34. 2020. Disponível em https://www.facebook.com/joserobertotorero Acesso 14 set. 2020.

GREIMAS, Algirdas Julien; COURTÉS, Joseph. Dicionário de semiótica. São Paulo: Contexto, 2008.

KLÜGER, Ruth. Paisagens da memória: autobiografia de uma sobrevivente do Holocausto. Trad. Irene Aron. São Paulo: 34, 2005.

LACOSTE, Charlotte. L'invention d'un genre littéraire : témoins de Jean Norton Cru. Texto!. v. 12. n. 3. 2007.

LANDOWSKI, Eric. Passions sans nom: essais de sócio-sémiotique III. Paris: PUF, 2004.

LANDOWSKI, Eric. Interações arriscadas. Trad. Luiza H. O. Silva. São Paulo: Estação das Letras e Cores; CPS, 2014.

LANDOWSKI, Eric. Regimes de espaço. Galáxia. n. 29. São Paulo: jun. 2015. p. 10-27.

LEVI, Primo. É isto um homem? Trad. Luigi Del Re. Rio de Janeiro: Rocco, 1988.

SILVA, Luiza Helena Oliveira da. Memórias da guerrilha: acontecimento e história. In: MENDES, Conrado Moreira; LARA, Glaucia Muniz Proença. (Orgs.). Em torno do acontecimento: uma homenagem a Claude Zilberberg. Curitiba: Appris, 2016. p. 141-162.

VALENTE, Rubens. Novo ministro já propôs escolha entre jovem e idoso "no fim da vida". UOL, São Paulo, 16 abr. 2020. Disponível em: https://noticias.uol.com.br/colunas/rubensvalente/2020/04/16/mandetta-coronavirus-saude.htm Acesso em 07 mai. 2020.

ZILBERBERG, Claude. Elementos de semiótica tensiva. Trad. Ivã Lopes, Luiz Tatit, Waldir Beividas. São Paulo: Ateliê, 2011 


\title{
(6) Readings and writings in times of pandemic: quarentenas, quarenteninhas and quaquarentenas, by Torero and Minkovicius
}

\author{
• (1) SILVA, Luiza Helena Oliveira
}

\begin{abstract}
This paper analyzes productions from three series of short chronicles written by José Roberto Torero Fernandes Junior and illustrated by Ivo Minkovicius, published daily on Facebook, throughout 2020, covering what we understand as three moments of perception of the pandemic caused by Covid 19 in Brazil, at least with regard to his experience in the metropolises. They are respectively called Quarentenas, Quarenteninhas and Quaquarentenas. Mobilizing reflections produced by the studies of testimony literature and semiotics, we analyze, from the reading of a literature linked to everyday life, the "translations" of the experience of living and feeling the event. As the duration of the pandemic is experienced, far beyond the most pessimistic predictions, there is an attenuation of feeling the initially impacting effect of its appearance, moving towards anesthesia that contributes to indifference as to its effects. Writing, however, is still insisting on the meaning.
\end{abstract}

Keywords: testimony literature; event; discursive semiotics; pandemic; Torero.

\section{Como citar este artigo}

SILVA, Luiza Helena Oliveira. Leituras e escrituras em tempos de pandemia. Quarentenas, Quarenteninhas e Quaquarentenas, de Torero e Minkovicius. Estudos Semióticos [online] Volume 17, número 1. São Paulo, abril de 2021. p. 107-123. Disponível em: <www.revistas.usp.br/esse>. Acesso em: dia/mês/ano.

\section{How to cite this paper}

SILVA, Luiza Helena Oliveira. Leituras e escrituras em tempos de pandemia. Quarentenas Quarenteninhas e Quaquarentenas, de Torero e Minkovicius. Estudos Semióticos [online]. Vol. 17.1. São Paulo, april 2021. p. 107-123. Retrieved from: <www.revistas.usp.br/esse>. Accessed: month/day/year.

Data de recebimento do artigo: 19/01/2021.

Data de aprovação do artigo: 31/01/2021.

Este trabalho está disponível sob uma Licença Creative Commons CC BY-NC-SA 4.0.

This work is licensed under a Creative Commons CC BY-NC-SA 4.0 License. 